\title{
Setting Overweight Adults in Motion: The Role of Health Beliefs
}

\author{
Eveline J.M. Wouters ${ }^{a, c} \quad$ Annemieke M.A. van Nunen ${ }^{d} \quad$ Ad J.J.M. Vingerhoets $^{a} \quad$ Rinie Geenen $^{b}$ \\ ${ }^{a}$ Clinical Psychology Section, Tilburg University, \\ ${ }^{\mathrm{b}}$ Department of Clinical and Health Psychology, Utrecht University, \\ ${ }^{\mathrm{C}}$ Fontys University of Applied Sciences, Department of Physiotherapy,

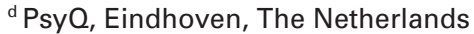

\section{Key Words}

Obesity · Overweight · Exercise · Cognition ·

Health behavior

\section{Summary}

Objective: Health beliefs of overweight adults who did and did not enter an exercise program were compared to identify possible factors that hamper people to enter such a program. Method: Participants $(n=116,78$ women and 38 men) were overweight adults without comorbidities. Self-report instruments examined the burden of suffering, beliefs related to physical exercise and obesity, somatic complaints, and obesity-related quality of life of new participants of exercise programs versus sedentary non-exercisers. Results: The mean BMI of exercisers and non-exercisers was $34.6 \pm 7.0$ and $32.8 \pm 5.8 \mathrm{~kg} / \mathrm{m}^{2}$, respectively. Fear of injury was higher and perceived health benefits of exercise were lower in the non-exercisers who also more often believed their overweight to be irreversible and attributed overweight to physical causes. The burden of suffering, somatic complaints, and quality of life of the groups were not significantly different. Fear of injury remained a significant predictor of belonging to the non-exercise group after controlling for other variables and multiple testing. Conclusion: Research is needed to examine whether the inflow of overweight people in exercise groups increases when health beliefs are recognized, considered, and discussed both in interventions and in public health campaigns promoting physical exercise in sedentary, overweight people.

\section{Introduction}

Overweight and obesity have become a prevalent problem $[1,2]$. Obesity is a risk factor of chronic diseases such as diabetes type 2 and cardiovascular disease [3]. Physical exercise programs have been demonstrated to reduce weight, to support preservation of the reduced weight [4-8], to reduce obesity-related health risks [9], and to improve mental health [10-12]. Although physical exercise is beneficial beyond doubt and large physical activity promotion programs have been implemented $[13,14]$, the majority of overweight persons does not engage in sportive activities [15]. In order to stimulate sedentary overweight persons to exercise, it is necessary to have insight into the characteristics that may hamper them to enter physical exercise programs.

Several theories specify determinants of health behavior. Two influential models have motivated the choice of variables in the current study: the health belief model $[16,17]$ and the self-regulation theory [18]. The health belief model states that the practice of a health behavior can be understood by knowing whether the person perceives a health threat as well as health benefits from a particular practice to reduce that threat. Four elements determine health practices: perceived threat, barriers, benefits, and cues to action [16]. 'Threat' refers to susceptibility, the perception of one's personal risk for contracting a certain health condition, and the perceived severity of this condition. Indeed, a major motivation of obese patients for seeking treatment in medical centers has been the threat of future health risks [19]. 'Barriers' in the health belief model are the possible negative consequences of particular health actions such as considering exercising risky, irrelevant, or unnecessary [20-22]. Other barriers applying to overweight are not being a sporty type, feeling lack of confidence or embarrassment to be seen exercising $[23,24]$, regarding oneself as unac-

\begin{tabular}{ll}
\hline KARGER & @ 2009 S. Karger GmbH, Freiburg \\
Fax +497614520714 & Accessible online at: \\
Information@Karger.de & www.karger.com/ofa \\
www.karger.com &
\end{tabular}


ceptably overweight [25], and the experience that exercise does not provide much pleasure $[20,26]$. 'Benefits' in the health belief model refer to the believed effectiveness of strategies to reduce the threat [17]. Perceived benefits of exercise predict physical exercise following counseling in primary care [27, 28]. 'Cues to action', the final element of the health belief model, can be any event both physical, e.g., disease symptoms, or environmental, e.g., illness in relatives, which motivates a person to change his or her lifestyle behavior. Also a perceived decrease in quality of life might be a cue to action. Quality of life is on average substantially impaired in obesity $[29,30]$ and improves after weight reduction [31]. Reduced quality of life and higher weight have been related to treatment seeking behavior in obesity [32,33], but it is not clear whether this also pertains to the willingness to enter a physical exercise program. All together there is reason to believe that threats, barriers, benefits, and cues to action may influence the motivation of sedentary overweight persons to increase their physical activity.

Besides the perception of health threats and benefits, other beliefs determine health behavior. Self-regulation theory distinguishes five illness representations or cognitions about the illness [18]: i) identity, the label of the threat, e.g., obesity and its symptoms, ii) timeline, the prognosis and changeability of the problem, iii) cause, the supposed origin, e.g., somatic/genetic or stress-induced, iv) consequences, the effects such as reduced functioning, and v) cure control, the extent to which the health problem can be cured, prevented, or kept from progressing. The predictive value of self-regulation cognitions in obese persons has been confirmed for the effect of dietary intervention [34]. The more one considered obesity to be unchangeable and to have a somatic rather than a behavioral origin, the more difficult it appeared to be to change one's behavior. If and how this applies to sedentary adults to start physical exercise is not known.

To be better able to incite overweight persons to enter an exercise program or to increase their physical activity level in another way, the aim of the present exploratory study was to identify the possible factors that hamper people to start a physical exercise program. To this end, we compared psychological scores of overweight, but otherwise healthy adults who did and did not participate in a physical exercise program. Several sociodemographic variables were examined as covariates due to their possible influence on motivation to engage in sportive activities, notably age and gender [35], education level [36], baseline physical activity [20], (disappointing) dietary experiences [37, 38], and obesity of the parents [39].

It was hypothesized that the following factors are related to starting physical exercise: considering overweight as a serious health problem (threat), the absence of fear of injury or embarrassment (barriers), a positive attitude towards exercise and confidence in exercise (health benefits), more health complaints, a lower perceived quality of life and more suffering and a higher BMI (cues), together with realistic self-regulative cognitions toward overweight.

\section{Participants and Methods}

\section{Participants and Procedure}

From April 2006 until December 2007, 58 participants who started exercising for the first time and 58 non-exercising (sedentary) overweight persons entered this study. Inclusion criteria were: age between 18 and 65 years, no serious health problems needing medical attention, a BMI of $25 \mathrm{~kg} / \mathrm{m}^{2}$ or more, and (for the non-exercisers only) no intention to reduce weight or improve health by any means including exercise since at least 1 year. The exercisers entered an exercise program in one of six participating fitness centers, predominantly in the Eindhoven region, the Netherlands. The centers did not focus on body building, but aimed at clients who wanted to improve their general health. The exercising participants filled out the questionnaire before the actual start of the exercise program. The non-exercising group was recruited through advertisements $(n=6)$, the website of the Dutch Obesity Society $(n=10)$, large sizes fashion shops $(n=16)$, general practitioners $(n=10)$, and acquaintances of the authors $(n=16)$. Participants were informed about the general purpose of the study, being 'research on physical and psychological aspects of physical activity in overweight persons'. Participants were volunteers, received no compensation for participation, and gave written informed consent before participating. One of the adults from the non-exercising group who were asked to participate and who met the inclusion criteria, refused participation for unknown reasons. The study was approved by the research and ethics committee of the Reinier van Arkel Group, 'sHertogenbosch, the Netherlands.

\section{Measures}

\section{General Characteristics}

Information about dieting history was obtained with questions such as 'Have you tried to lose weight in the past?' and 'How long did your weight loss attempts last on average?'. Information of occurrence and extent of overweight in father and mother was obtained with two questions. An example question is: 'Was your biological father overweight at any time during his life and if so, to what extent?'. Respondents answered with a five-point scale response format, ranging from 'no overweight' to 'more overweight than mine'. Recent and current exercise behavior was measured by asking 'Do you engage in sportive activities?'(answering possibilities yes or no), an open-ended question about the nature of these activities and the time spent to these activities weekly during the past year, using a five-point scale response format ranging from 'less than $1 \mathrm{~h} /$ week' to 'more than $4 \mathrm{~h} /$ week'. Walking and cycling activities during daily life, like shopping, going to work or going to school, were rated on a five-point scale, ranging from less than $5 \mathrm{~min} /$ day to more than $45 \mathrm{~min} /$ day.

\section{Suffering}

Suffering and perceived medical problem were measured with the Pictorial Representation of Illness and Self Measure, 2nd revision (PRISM-R2) [40,41]. The PRISM-R2 consists of a rectangular (A4) sheet of paper, with a large (diameter $186 \mathrm{~mm}$ ) circle depicting the persons life environment, with a yellow disk in the middle (diameter $52 \mathrm{~mm}$ ), representing the person's 'self', and three differently sized $(35,52$ or $65 \mathrm{~mm})$ separately provided auto-adhesive disks representing the medical problem (in this study overweight or obesity). Participants are asked to choose which of these three disks best mirrors how they perceive their overweight. A larger size of this medical problem disc (IPM = Illness Perception Measure) represents more perceived severity of the overweight problem and applies to the 'threat' concept of the health belief model. Having chosen the most appropriate disk, they attach it to the paper sheet in such a way that it best typifies the participant's current view of the place of the medical problem in her or his life. A smaller distance between the centers of the 'self' and medical problem disks (SIS = Self-Illness Separation) indicates more suf- 
fering, and is considered as a 'cue to action' in the health belief model. The feasibility and validity of the variables assessed by the PRISM-R2 in measuring aspects of suffering in obesity have been supported [41].

\section{Physical Exercise Beliefs}

Perceived benefits and barriers of physical exercise were measured with the Physical Exercise Belief Questionnaire (PEBQ) [22]. This 16-item questionnaire, which is partly based on the Dutch version of the Tampa Scale for Kinesiophobia (TSK) [22], consists of four scales. Two scales assess barriers to physical exercise: fear of injury (e.g. 'Sports are dangerous for me because I easily get injured') and embarrassment (e.g. 'I feel ashamed of my body when doing sports'). Two other scales measure perceived exercise benefits (e.g. 'Sports are healthy for me') and confidence (e.g. 'I am a sporty type of person'). The five-point Likert rating format ranges from 1 (strongly disagree) to 5 (strongly agree). The psychometric characteristics of the PEBQ have been found to be satisfactory [22]. In the current study, Cronbach's $\alpha$ values were 0.65 for exercise benefits, 0.93 for embarrassment, and 0.80 for fear of injury and confidence.

\section{Somatic Complaints}

Somatic complaints were assessed with a questionnaire listing 10 obesityrelated complaints (e.g. joint problems, back complaints, varicose veins, fatigue). This questionnaire has a five-point rating format, ranging from 1 (not at all) to 5 (very much)

\section{Quality of Life}

Quality of life was measured with the Impact of Weight on Quality of Life-Lite questionnaire (IWQOL-Lite), which contains five scales: physical function (e.g. 'Because of my weight I have trouble using stairs'), self esteem (e.g. 'Because of my weight I am embarrassed to be seen in public places'), sexual life (e.g. 'Because of my weight I do not enjoy sexual activity'), public distress (e.g. 'Because of my weight I experience ridicule, teasing, or unwanted attention') and work (e.g. 'Because of my weight I am afraid to go on job interviews') [42]. The total score summarizes the overall impact of overweight on quality of life. The IWQOL-Lite has been proven to be a reliable and valid instrument to measure obesityrelated quality of life in both community and treatment samples of obese persons [42]. Cronbach's $\alpha$ coefficients in our sample were 0.73 for work and between 0.88 and 0.94 for the other four scales.

\section{Obesity Cognitions}

Obesity cognitions were studied with the Obesity Cognition Questionnaire (OCQ) [43], an obesity-adapted version of the Illness Perception Questionnaire (IPQ) [44]. The OCQ consists of 25 items and four scales for timeline, physical cause, behavioral cause, and psychological consequences. High scores on timeline reflect a pessimistic perception of the prognosis of one's overweight. High scores on physical cause and behavioral cause indicate that one considers physical and behavioral causes of obesity important, respectively. High scores on psychological consequences reflect the psychological impact of obesity [45]. The psychometric properties of the OCQ are adequate. In our study the scales had a moderate to high internal consistency; Cronbach's $\alpha$ ranged between 0.66 for physical origin and 0.80 to 0.82 for the other scales.

\section{Statistical Analyses}

With exception of the scores on the IWQOL-Lite and number of com plaints, the scores were normally or nearly normally distributed according to common criteria [46]. Participants' characteristics and the study variables of the exercise and non-exercise groups were statistically compared with chi-square tests in case of nominal variables, with non-parametric (Mann-Whitney U) tests in case of the not normally distributed variables, and independent samples $t$ test in case of the other variables. The magnitude of differences was computed (Cohen's d) in normally distributed variables [47]; these effect sizes express the magnitude of differences be- tween groups in standard deviation units. Effect sizes from 0.2 to 0.5 , from 0.5 to 0.8 and greater than 0.8 are considered small, moderate and large, respectively. A logistic regression analysis was performed to identify factors that significantly differentiated between exercisers and non-exercisers while adjusting for other variables; only variables that significantly $(\mathrm{p}<0.05)$ discriminated between the exercising and non-exercising group were entered into the regression model. To take account of multiple testing, the Bonferroni criterion (the normal $\mathrm{p}$ value divided by the number of tests) was used to interpret findings in case of significance.

\section{Results}

\section{General Characteristics of the Participants}

Table 1 shows the characteristics of the exercising and nonexercising participants. The groups did not differ significantly with respect to education level, age or BMI, but there was a significant difference with respect to gender: the percentage of women in the exercise group exceeded the percentage of women in the non-exercise group $(\mathrm{p}=0.006)$. Fathers of research participants in the non-exercise group were reported by the participants to be more overweight $(p=0.04)$, whereas the prevalence and severity of overweight mothers was not different. We did not find differences in dieting history with respect to occurrence of dieting attempts, mean duration of attempts, occurrence of weight cycling, current sportive activities, or physical exercise in daily life. The sportive activities most often mentioned, both in the physical exercise group and the non- exercising participants, were leisure (unorganized) walking, cycling, and swimming activities. There was no difference in time of onset of overweight between the groups: in approximately $40 \%$ of both groups overweight had started in childhood or adolescence.

\section{Main Results}

Table 2 shows the means of the exercising and non-exercising participants with respect to suffering and perceived medical problems, physical exercise beliefs, somatic complaints, quality of life, and obesity cognitions.

The difference between both groups for the variables on suffering and perceived severity (PRISM-R2) was not significant.

Exercisers reported less fear of injury than non-exercisers $(p<0.001)$ and anticipated more health benefits as a result of physical exercise $(\mathrm{p}=0.03)$. The two groups did not differ with respect to embarrassment and exercise confidence.

The amount and nature of somatic complaints not needing medical attention did not differ between both groups. The main problems in order of frequency were: fatigue (more than two thirds in both groups), joint and back problems (over $50 \%$ ) and shortness of breath (almost half of all participants).

The total quality of life score was not significantly lower in the group of exercisers $(p=0.057)$. Self-esteem was significantly lower in the exercise group $(\mathrm{p}=0.046)$. Group differences on the other quality of life dimensions failed to reach significance. 
Table 1. General characteristics of 58 exercise starting and 58 non-exercising participants

\begin{tabular}{|c|c|c|c|c|}
\hline & Exercise group & Non-exercise group & $\mathrm{t} / \mathrm{U} / \mathrm{X}^{2}$ & $\mathrm{p}$ \\
\hline Gender (female) $)^{\mathrm{a}}, \mathrm{n}(\%)$ & $46(79 \%)$ & $32(55 \%)$ & 7.61 & 0.006 \\
\hline Education level $^{\mathrm{b}}, \mathrm{n}(\%)$ & & & 1,371 & 0.08 \\
\hline Primary & $8(14 \%)$ & $6(10 \%)$ & & \\
\hline Secondary & $33(57 \%)$ & $26(45 \%)$ & & \\
\hline Tertiary & $17(29 \%)$ & $26(45 \%)$ & & \\
\hline $\mathrm{Age}^{\mathrm{c}}$, mean $(\mathrm{SD})$ years & $44(11)$ & $42(11)$ & 1.17 & 0.24 \\
\hline $\mathrm{BMI}^{\mathrm{c}}$, mean $(\mathrm{SD}) \mathrm{kg} / \mathrm{m}^{2}$ & $34.6(7.0)$ & $32.8(5.8)$ & 1.51 & 0.13 \\
\hline Onset overweight $^{\mathrm{b}}$ & & & 1,675 & 0.97 \\
\hline $0-6$ years & $6(10 \%)$ & $5(8 \%)$ & & \\
\hline $6-11$ years & $7(12 \%)$ & $8(14 \%)$ & & \\
\hline $11-18$ years & $11(19 \%)$ & $11(19 \%)$ & & \\
\hline$>18$ years & $34(59 \%)$ & $34(59 \%)$ & & \\
\hline Overweight father ${ }^{\mathrm{b}}, \mathrm{n}(\%)$ & & & 1,309 & 0.04 \\
\hline None & $23(40 \%)$ & $17(29 \%)$ & & \\
\hline Some & $21(36 \%)$ & $17(29 \%)$ & & \\
\hline Substantial, less than mine & $5(9 \%)$ & $7(12 \%)$ & & \\
\hline Substantial, comparable to mine & $6(10 \%)$ & $10(17 \%)$ & & \\
\hline Substantial, more than mine & $0(0 \%)$ & $5(9 \%)$ & & \\
\hline Unknown & $3(5 \%)$ & $2(4 \%)$ & & \\
\hline Overweight mother ${ }^{\mathrm{b}}, \mathrm{n}(\%)$ & & & 1,644 & 0.96 \\
\hline None & $15(26 \%)$ & $16(28 \%)$ & & \\
\hline Some & $17(29 \%)$ & $16(28 \%)$ & & \\
\hline Substantial, less than mine & $10(17 \%)$ & $7(12 \%)$ & & \\
\hline Substantial, comparable to mine & $6(10 \%)$ & $11(19 \%)$ & & \\
\hline Substantial, more than mine & $9(16 \%)$ & $5(8 \%)$ & & \\
\hline Unknown & $1(2 \%)$ & $3(5 \%)$ & & \\
\hline \multicolumn{5}{|l|}{ Dietary history } \\
\hline Dietary attempts in past ${ }^{\mathrm{a}}, \mathrm{n}(\%)$ & & & 2.18 & 0.14 \\
\hline Yes & $51(88 \%)$ & $45(78 \%)$ & & \\
\hline No & $7(12 \%)$ & $13(22 \%)$ & & \\
\hline Duration attempt in weeks ${ }^{\mathrm{c}}$, mean (SD) & $14.0(13.7)$ & $16.4(19.3)$ & -0.66 & 0.51 \\
\hline Weight cycling $^{\mathrm{a}}$ & & & 2.49 & 0.29 \\
\hline Yes & 32 & 22 & & \\
\hline No & 19 & 21 & & \\
\hline
\end{tabular}

Other physical activities

Involvement in sportive activities Yes

No

Time spent weekly on sportive activities ${ }^{\mathrm{b}}$

$$
\begin{aligned}
& <1 \mathrm{~h} / \text { week } \\
& 1-2 \mathrm{~h} / \text { week } \\
& 2-3 \mathrm{~h} / \text { week }
\end{aligned}
$$

3-4 h/week

Time spent on daily walking and cycling ${ }^{\mathrm{b}}$

$$
<5 \text { min }
$$

5-15 min

15-30 $\mathrm{min}$

30-45 $\mathrm{min}$

$>45 \mathrm{~min}$

$\mathrm{X}^{2}$ test.

${ }^{\mathrm{b}}$ Mann-Whitney U test.

${ }^{\mathrm{c}}$ Independent $\mathrm{t}$ test.
$27(47 \%)$

$31(53 \%)$

$1.18 \quad 0.18$

$18(31 \%)$

$40(69 \%)$

$6(22 \%) \quad 3(17 \%)$

$5(19 \%) \quad 3(17 \%)$

$4(15 \%) \quad 2(11 \%)$

$14(24 \%) \quad 14(24 \%)$

$17(29 \%) \quad 10(17 \%)$

$11(19 \%) \quad 8(14 \%)$

$7(12 \%) \quad 20(35 \%)$

$9(16 \%) \quad 6(10 \%)$

$12(44 \%) \quad 10(55 \%)$ 
Table 2. Means and medians of exercising and non-exercising overweight participants with respect to suffering, physical exercise beliefs, complaints, quality of life, and obesity cognitions*

\begin{tabular}{|c|c|c|c|c|c|}
\hline & $\begin{array}{l}\text { Exercise } \\
\text { starting group }\end{array}$ & $\begin{array}{l}\text { Non-exercise } \\
\text { group }\end{array}$ & $\mathrm{t} / \mathrm{U}$ & $\mathrm{p}^{\mathrm{a}}$ & Cohen's d ${ }^{b}$ \\
\hline \multicolumn{6}{|l|}{$\begin{array}{l}\text { Perceived medical problem and suffering } \\
\text { (PRISM-R2) }\end{array}$} \\
\hline IPM, mean (SD), range $1-3$ & $1.9(0.8)$ & $1.6(0.8)$ & 1.95 & 0.05 & 0.37 \\
\hline SIS, mean (SD), mm & $26(25)$ & $33(22)$ & -1.71 & 0.09 & 0.32 \\
\hline \multicolumn{6}{|l|}{ Physical exercise belief (PEBQ) } \\
\hline Fear of injury, mean (SD) & $7.3(3.6)$ & $10.3(4.1)$ & -4.21 & $<0.001$ & 0.77 \\
\hline Embarrassment,mean (SD) & $10.2(5.7)$ & $9.5(5.1)$ & 0.73 & 0.47 & 0.14 \\
\hline Exercise benefits, median (IR) & $18.1(2.0)$ & $17.1(2.4)$ & 2.26 & 0.03 & 0.42 \\
\hline Confidence, mean (SD) & $8.7(3.1)$ & $8.2(3.3)$ & 0.90 & 0.37 & 0.17 \\
\hline Somatic complaints, median (IR), range $11-55$ & $14(6)$ & $14(3)$ & 1,316 & 0.18 & \\
\hline \multicolumn{6}{|l|}{ Quality of life (IWQOL-Lite) } \\
\hline Physical function, mean (SD) & $69.0(20.0)$ & $74.8(18.6)$ & -1.68 & 0.10 & 0.32 \\
\hline Self esteem,mean (SD) & $64.0(27.7)$ & $74.3(27.2)$ & -2.01 & 0.05 & 0.37 \\
\hline Sexual life, median (IR) & $81.3(34.4)$ & $100.0(18.8)$ & 1,319 & 0.09 & \\
\hline Public distress, median (IR) & $92.5(30.0)$ & $95.0(20.0)$ & 1,543 & 0.42 & \\
\hline Work, median (IR) & $93.8(18.8)$ & $100.0(9.4)$ & 1,381 & 0.13 & \\
\hline Total, mean (SD) & $74.2(15.9)$ & $84.7(22.6)$ & 1,133 & 0.06 & 0.37 \\
\hline \multicolumn{6}{|l|}{ Obesity cognitions (OCQ) } \\
\hline Time-line, mean (SD) & $15.1(3.7)$ & $17.9(4.2)$ & -3.80 & $<0.001$ & 0.71 \\
\hline Physical cause, mean (SD) & $10.0(3.0)$ & $11.7(3.9)$ & -2.54 & 0.01 & 0.50 \\
\hline Behavioral cause, mean (SD) & $20.4(3.1)$ & $19.1(4.1)$ & 1.99 & 0.05 & 0.39 \\
\hline Psychological consequences, mean (SD) & $26.1(6.2)$ & $23.9(8.2)$ & 1.69 & 0.12 & 0.32 \\
\hline
\end{tabular}

IPM = Illness Perception Measure; SIS = Self-Illness Separation.

*As measures of central tendency (M) and spread, for somatic complaints, the IWQOL-Lite scales sexual life, work, and public distress, medians and interquartile ranges (IR) are presented. For all other variables means and standard deviations (SD) are presented. Better functioning is represented by higher values at the IWQOL-Lite, and PEBQ exercise benefits and confidence, OCQ behavioral cause, and PRISM-R2 distance (SIS). Better functioning is represented by lower scores at PEBQ fear of injury and embarrassment, OCQ physical cause and time-line, and PRISM-R2 subjective illness severity (IPM);

${ }^{\mathrm{a}} \mathrm{p}$ values were calculated with Mann-Whitney $\mathrm{U}$ tests $(\mathrm{U})$ for skewed variables and $\mathrm{t}$ tests $(\mathrm{t})$ for normally distributed variables

${ }^{\mathrm{b}}$ Cohen's d was calculated in normally distributed variables.
Table 3. Predictors of membership of the non-exercising group

\begin{tabular}{lrlll}
\hline Variable & \multicolumn{1}{c}{$\mathrm{B}$} & $\mathrm{SE}$ & $\mathrm{p}$ & $\mathrm{OR}$ \\
\hline Gender & 1.67 & 0.51 & 0.01 & 5.30 \\
Overweight father & 0.29 & 0.17 & 0.10 & 1.33 \\
Exercise benefits (PEBQ) & -0.16 & 0.12 & 0.17 & 0.85 \\
Fear of injury (PEBQ) & 0.18 & 0.07 & 0.007 & 1.20 \\
Timeline (OCQ) & 0.13 & 0.07 & 0.06 & 1.14 \\
Physical cause (OCQ) & 0.08 & 0.08 & 0.28 & 1.09 \\
\hline
\end{tabular}

$\mathrm{PEBQ}=$ Physical exercise belief questionnaire; $\mathrm{OCQ}=$ obesity cognition questionnaire; $\mathrm{OR}=$ odds ratio.

The groups differed significantly on three of the four obesity cognitions. As compared to the non-exercisers, the exercisers had lower scores on timeline $(\mathrm{p}<0.001)$ and somatic cause $(\mathrm{p}=0.01)$ and higher scores on behavioral cause $(\mathrm{p}=$ 0.049), which indicated that they were more optimistic about the changeability and the controllability of their overweight problem.

After application of the Bonferroni criterion for multiple testing ( $p=0.001)$, fear of injury and timeline were still discriminating between exercisers and non exercisers.

Variables that were significantly different between the exercising group and the non-exercising group were entered into a logistic regression model. These variables were: gender, overweight of the father, fear of injury, exercise benefits as well as the obesity cognitions timeline and physical cause. The results are presented in table 3. While controlling for other variables in the model, male gender (OR 5.30, 95\% CI 1.97-14.25) and fear of injury remained significant predictors of belonging to the non-exercise group (OR 1.20, CI 1.05-1.36). The examination of possible interaction effects between each relevant psychological predictor and overweight of the father revealed no significant interactions. 


\section{Discussion}

Health beliefs of overweight adults who did and did not participate in a physical exercise program were compared with the aim to identify possible factors that hamper people to start physical exercise. Account was taken of sociodemographic factors. Fear of injury was higher and perceived health benefits were lower in the non-exercisers, who also more often attributed their overweight to physical causes and believed overweight to be irreversible. The burden of suffering, somatic complaints, and quality of life of the groups were not significantly different. Exercisers, as compared to non-exercisers, were more often female and had fathers with less overweight. Body weight, age, and education level of the groups were comparable. Fear of injury remained a significant predictor of belonging to the non-exercise group after controlling for other variables and multiple testing.

\section{General Characteristics}

Of the demographic variables, female gender predicted exercise group membership. This observation is concordant with previous observations: women tend to utilize health care services more extensively [48], obese treatment populations include far more women than men [30], women tend to have a stronger belief in the benefits of healthy eating [49], and women are more motivated to a healthy lifestyle, including being physically active [50]. Our finding and these previous findings stress that a great challenge in health education, including promotion of physical activity, is to try to set overweight men in motion.

Overweight of fathers, but not of mothers, was observed to be more prevalent and severe in the non-exercising group. Perhaps the fathers of this generation were more than the mothers concerned with encouraging their children in physical activities, especially the less obese fathers. Further research is needed to corroborate this finding.

\section{Health Belief Model: Threat}

The 'threat' component of the health belief model, measured as perceived severity of the overweight, was not significantly higher in the exercise group. In our study, the exclusion of research participants with serious health problems may have prevented a significant finding. Probably the absence of a health threat perception until comorbidities occur may partly explain why overweight people do not start increasing their physical activities to improve their health.

\section{Health Belief Model: Barriers}

We examined embarrassment and fear for injury as potential 'barriers' for physical exercise. Among female undergraduates, weight stigma experiences were related to physical exercise avoidance [51], but the embarrassment of adults in our research population did not differentiate between exercisers and non-exercisers and thus could not be considered a major barri- er. A main finding of our study is that non-exercisers reported substantially more fear of injury. The role of fear and its consequences for exercise performance has been extensively examined in patients with chronic pain and is explained by the fear avoidance model [52]. The model explicates that, if pain is (mis)interpreted as being threatening, avoidance of physical activity will result and this will subsequently have a negative impact on musculoskeletal function, physical performance and fitness [53]. In morbidly obese patients after bariatric surgery, fear of injury was a predictor of reduced physical exercise [22]. Our study suggests that, similar as in chronic pain patients and morbidly obese patients, fear of injury might be a major barrier of engaging in physical activity and contributes to the sedentary state of overweight individuals. As has been suggested [26, 54, 55], graded exercise programs and education about fear avoidance will likely increase the engagement in physical activity and improve the treatment results in overweight persons.

\section{Health Belief Model: Benefits}

'Benefits' in the health belief model refer to the believed effectiveness of strategies to reduce the threat [17]. Positive cognitions about one's capability to perform physical activity will increase the chance of getting engaged in physical exercise. In our study, confidence in perceived sportive abilities did not differ between groups, but persons who did not make the move to start organized physical exercise were less convinced that exercise would contribute to a better health. Logistic regression analysis suggested that the negative motivation to not exercise (fear for injury) is a more distinctive feature between exercisers and non-exercisers than the positive motivation of future health benefits.

\section{Health Belief Model: Cues to Action}

A primary motivation (cue) for obese individuals to decide to participate in weight loss treatment in medical centers is health impairment $[19,56]$. In the present study, most participants confirmed that a main reason for starting physical exercise now or in future was or would be actual or possible health risks, but the exercise and non-exercise group did not differ in this respect. In addition, in contrast to expectation [32], actual health problems did not differ between the two groups, likely due to the exclusion of participants who where under medical supervision. A low quality of life and more suffering were hypothesized to be additional cues for the decision to participate in a physical exercise program, as was observed for patients seeking treatment for obesity [32, 33]. However, our data did not support this hypothesis. Also BMI, another possible cue, did not differentiate between the groups. Overall, our data do not clearly support the notion that physical health problems or quality of life might differentiate between overweight people who do and do not decide to start physical exercise. These factors may stimulate the initiation of health behavior only when the weight and health problems are extensive and qual- 
ity of life is more severely disturbed than in the participants of the current study $[30,33]$. When the high prevalence of overweight and moderate obesity in current society [2] is partly due to its relatively low interference with health and quality of life [57], preventive measures should use the threat of future consequences instead of current consequences as cues to stimulate physical exercise.

\section{Self-Regulatory Model: Obesity Cognitions}

Several other beliefs about overweight and self-regulatory capacities were hypothesized to differentiate between overweight persons who did and did not participate in physical training groups: the label of the threat, its timeline, the believed causes (somatic or behavioral) and consequences [18]. In our study the non-exercisers considered their overweight to be a more stable characteristic with a less positive prognosis; they tended to attribute their overweight to a physical cause and considered themselves unable to control their overweight problem. These results suggest the importance of addressing these cognitions in education and treatment programs for overweight, including physical exercise programs.

\section{Limitations}

There are several limitations to our study. First, the weight and height data were based on self-report, not on direct measurements. However, measured and self-reported weight are highly correlated, even up to $r=0.98[22,58]$. A second limitation of our study is that the participants of the two groups were differently selected. Participants in the exercise group were personally asked by their fitness instructor to participate, whereas the control group was recruited in several manners. Those participants who were recruited by way of advertisements and the Dutch Obesity Society $(n=16)$ were not asked personally and therefore might form a distinct group. It is not clear whether the overrepresentation of women in the exercise group is a consequence of selection bias or a true difference. An indication that the gender difference is based on a true difference, is the empirical observation that women are more motivated to participate in healthy behavior such as exercise and that obese women far more often enter treatment programs $[30,50]$. A third limitation of the study is that its exploratory character aimed at finding possible variables that play a role in the sedentary behavior bears the risk of overes- timating differences between the two groups due to multiple testing. However, the differences in fear of injury and timeline were also significant after Bonferroni correction. Moreover, as a result of the small sample size of the study, the risk of type I error findings is relatively small.

\section{Recommendation}

A strong feature of our study is that the outcome variable differentiated between groups that actually did and did not attend a physical exercise program instead of differentiating between self-reported physical exercise or intention to exercise. Future studies employing a prospective design could further analyze causative relations by offering physical exercise activities to overweight persons of the same population (e.g. a primary health care population) and evaluate who do and do not accept the offer. Moreover, besides exercise programs in fitness centers, prospective studies could include health promotion activities aimed at lifestyle changes.

\section{Conclusion}

Over and above by being more often male, overweight people not entering an exercise program differed from people who did enter an exercise program with respect to health beliefs - most clearly fear of injury. Research is needed to examine whether the inflow of overweight people in exercise groups increases when health beliefs are recognized, considered and discussed, both in individual contacts and public health campaigns promoting physical exercise in sedentary, overweight people.

\section{Acknowledgement}

The authors would like to acknowledge Thermae Son, Fitness First, de Brug Active, the Dutch Obesity Society, Big Sizes Eindhoven, Frits Niemans, Susan Seyrich, Pieter Hoff, Marijke Moonen, Sarah Notenboom, Suzan Geraerts, Sanne Joosten, Ilse Lameijer, Susan Looijmans, Ilse Griens, Antal Hellings, Renske van der Werf, Diderik Dellebeke, for help with data collection, and to thank all participants for taking part in this study.

\section{Disclosure}

The authors declared no conflicts of interest

\section{References}

1 Popkin BM: Global nutrition dynamics: the world is shifting rapidly toward a diet linked with noncommunicable diseases. Am J Clin Nutr 2006;84:289298

2 Schokker DF, Visscher TL, Nooyens AC, van Baak MA, Seidell JC: Prevalence of overweight and obesity in the Netherlands. Obes Rev 2007;8:101107.
3 Pardo Silva MC, De Laet C, Nusselder WJ, Mamun AA, Peeters A: Adult obesity and number of years lived with and without cardiovascular disease. Obesity (Silver Spring) 2006;14:1264-1273.

4 Befort CA, Stewart EE, Smith BK, Gibson CA, Sullivan DK, Donnelly JE: Weight maintenance, behaviors and barriers among previous participants of a university-based weight control program. Int J Obes (Lond) 2008:32:519-526.
5 Catenacci VA, Wyatt HR: The role of physical activity in producing and maintaining weight loss. Nat Clin Pract Endocrinol Metab 2007;3:518-529.

6 Ross R, Freeman JA, Janssen I: Exercise alone is an effective strategy for reducing obesity and related comorbidities. Exerc Sport Sci Rev 2000;28: 165-170. 
7 Ross R, Janssen I, Dawson J, Kungl AM, Kuk JL, Wong SL, Nguyen-Duy TB, Lee S, Kilpatrick K Hudson R: Exercise-induced reduction in obesity and insulin resistance in women: a randomized controlled trial. Obes Res 2004;12:789-798.

8 Villanova N, Pasqui F, Burzacchini S, Forlani G Manini R, Suppini A, Melchionda N, Marchesini G A physical activity program to reinforce weight maintenance following a behavior program in overweight obese subjects. Int J Obes (Lond) 2006;30:697-703.

9 Ekelund U, Franks PW, Sharp S, Brage S, Wareham NJ: Increase in physical activity energy expenditure is associated with reduced metabolic risk independent of change in fatness and fitness. Diabetes Care 2007;30:2101-2106.

10 Koeppl PM, Heller J, Bleecker ER, Meyers DA, Goldberg AP, Bleecker ML: The influence of weight reduction and exercise regimes upon the personality profiles of overweight males. J Clin Psychol 1992;48:463-471.

11 Bowen DJ, Fesinmeyer MD, Yasui Y, Tworoger S, Ulrich CM, Irwin ML, Rudolph RE, LaCroix KL, Schwartz RR, McTiernan A: Randomized trial of exercise in sedentary middle aged women: effects on quality of life. Int J Behav Nutr Phys Act 2006;3:34.

12 Annesi JJ: Relations of mood with body mass index changes in severely obese women enrolled in a supported physical activity treatment. Obes Facts 2008;1:88-92.

13 Aittasalo M, Miilunpalo S, Stahl T, KukkonenHarjula K: From innovation to practice: initiation, implementation and evaluation of a physicianbased physical activity promotion programme in Finland. Health Promot Int 2007;22:19-27.

14 Ronda G, Van Assema P, Candel M, Ruland E, Steenbakkers M, Van Ree J, Brug J: The dutch heart health community intervention 'Hartslag Limburg': Results of an effect study at individual level. Health Promot Int 2004;19:21-31.

15 Kruger J, Yore MM, Kohl HW 3rd: Physical activity levels by body mass index and weight contro status, among adults-national health and nutrition examination survey 1999-2004. Int J Behav Nutr Phys Act 2008;5:25.

16 Rosenstock IM: Historical origins of the health belief model. Health Educ Monogr 1974;2:328-335.

17 Becker H: The Health Belief Model and Persona Health Behavior. Thorofare, Charles B. Slack inc., 1974

18 Leventhal H, Leventhal EA, Contrada RJ: Selfregulation, health and behavior: a perceptual-cognitive approach. Psychol Health 1998;13:717-733.

19 Dalle Grave R, Calugi S, Molinari E, Petroni ML, Bondi M, Compare A, Marchesini G: Weight loss expectations in obese patients and treatment attrition: an observational multicenter study. Obes Res 2005;13:1961-1969.

20 Vanden Auweele Y, Rzewnicki R, Van Mele V: Reasons for not exercising and exercise intentions: a study of middle-aged sedentary adults. J Sports Sci 1997;15:151-165.

21 O'Brien Cousins S, Gillis MM: 'Just do it before you talk yourself out of it': the self-talk of adults thinking about physical activity. Psychol Sport Exerc 2005;6:313-334.

22 Larsen JK, Geenen R, van Ramshorst B, Brand N, Hox JJ, Stroebe W, van Doornen LJ: Binge eating and exercise behavior after surgery for severe obesity: a structural equation model. Int J Eat Disord 2006:39:369-375.

23 Jewson E, Spittle M, Casey M: A preliminary analysis of barriers, intentions, and attitudes towards moderate physical activity in women who are overweight. J Sci Med Sport 2008;11:558-561.
24 Biddle SJ, Fox KR: Motivation for physical activity and weight management. Int J Obes Relat Metab Disord 1998;22(suppl 2):S39-S47.

25 Atlantis E, Barnes EH, Ball K: Weight status and perception barriers to healthy physical activity and diet behavior. Int J Obes (Lond) 2008;32:343-352.

26 Ekkekakis P, Lind E: Exercise does not feel the same when you are overweight: the impact of selfselected and imposed intensity on affect and exertion. Int J Obes (Lond) 2006;30:652-660.

27 Steptoe A, Rink E, Kerry S: Psychosocial predictors of changes in physical activity in overweight sedentary adults following counseling in primary care. Prev Med 2000;31:183-194

28 Conn VS, Tripp-Reimer T, Maas ML: Older women and exercise: theory of planned behavior beliefs. Public Health Nurs 2003;20:153-163.

29 Kolotkin RL, Meter K, Williams GR: Quality of life and obesity. Obes Rev 2001;2:219-229.

30 Van Nunen AM, Wouters EJ, Vingerhoets AJ, Hox JJ, Geenen R: The health-related quality of life of obese persons seeking or not seeking surgical or non-surgical treatment: a meta-analysis. Obes Surg 2007;17:1357-1366.

31 Kolotkin RL, Crosby RD, Williams GR, Hartley GG, Nicol S: The relationship between healthrelated quality of life and weight loss. Obes Res 2001;9:564-571.

32 Fontaine KR, Bartlett SJ, Barofsky I: Health-related quality of life among obese persons seeking and not currently seeking treatment. Int J Eat Disord 2000;27:101-105.

33 Kolotkin RL, Crosby RD, Williams GR: Health-related quality of life varies among obese subgroups. Obes Res 2002;10:748-756.

34 Wamsteker EW, Geenen R, Iestra J, Larsen JK, Zelissen PM, van Staveren WA: Obesity-related beliefs predict weight loss after an 8-week lowcalorie diet. J Am Diet Assoc 2005;105:441-444.

35 Cardinal BJ, Lee JY, Kim YH, Lee H, Li KK, Si Q: Behavioral, demographic, psychosocial, and sociocultural concomitants of stage of change for physical activity behavior in a mixed-culture sample. Am J Health Promot 2009;23:274-278.

36 Shaw BA, Spokane LS: Examining the association between education level and physical activity changes during early old age. J Aging Health 2008;20:767-787.

37 Teixeira PJ, Going SB, Houtkooper LB, Cussler EC, Martin CJ, Metcalfe LL, Finkenthal NR, Blew RM, Sardinha LB, Lohman TG: Weight loss readiness in middle-aged women: psychosocial predictors of success for behavioral weight reduction. J Behav Med 2002;25:499-523.

38 Teixeira PJ, Palmeira AL, Branco TL, Martins SS, Minderico CS, Barata JT, Silva AM, Sardinha LB: Who will lose weight? A reexamination of predictors of weight loss in women. Int J Behav Nutr Phys Act 2004;1:12.

39 Bautista-Castano I, Molina-Cabrillana J, MontoyaAlonso JA, Serra-Majem L: Variables predictive of adherence to diet and physical activity recommendations in the treatment of obesity and overweight, in a group of Spanish subjects. Int J Obes Relat Metab Disord 2004;28:697-705.

40 Buchi S, Buddeberg C, Klaghofer R, Russi EW, Brandli O, Schlosser C, Stoll T, Villiger PM, Sensky $\mathrm{T}$ : Preliminary validation of prism (pictorial representation of illness and self measure) - a brief method to assess suffering. Psychother Psychosom 2002; 71:333-341.
41 Wouters EJ, Reimus JL, van Nunen AM, Blokhorst MG, Vingerhoets AJ: Suffering quantified? Feasibility and psychometric characteristics of 2 revised versions of the pictorial representation of illness and self measure (PRISM). Behav Med 2008;34:65-78.

42 Kolotkin RL, Crosby RD: Psychometric evaluation of the impact of weight on Quality of Life-Lite questionnaire (IWQOL-Lite) in a community sample. Qual Life Res 2002;11:157-171.

43 Zijlstra H, Larsen JK, van Ramshorst B, Geenen $\mathrm{R}$ : The association between weight loss and selfregulation cognitions before and after laparoscopic adjustable gastric banding for obesity: a longitudinal study. Surgery 2006;139:334-339.

44 Weinman J, Petrie KJ, Moss-Morris R, Horne R: The illness perception questionnaire: new method for assessing the cognitive representation of illness. Psychol Health 1996;11:431-445.

45 Warmsteker EW, Geenen R, Zelissen PM, van Furth EF, Iestra J: Unrealistic weight loss goals among obese patients are associated with age and causal attributions. J Am Diet Assoc 2009;109:1903-1908.

46 Tabachnick B, G, Fidell LS: Using Multivariate Statistics. Boston, Allyn and Bacon, 2001.

47 Cohen J: Statistical Power Analysis for the Behavioural Sciences, 2nd ed. Hillsdale, Lawrence Erlbaum Associates, 1988.

48 Kandrack MA, Grant KR, Segall A: Gender differences in health related behaviour: some unanswered questions. Soc Sci Med 1991;32:579-590.

49 Wardle J, Haase AM, Steptoe A, Nillapun M, Jonwutiwes K, Bellisle F: Gender differences in food choice: the contribution of health beliefs and dieting. Ann Behav Med 2004;27:107-116.

50 Von Bothmer MI, Fridlund B: Gender differences in health habits and in motivation for a healthy lifestyle among Swedish university students. Nurs Health Sci 2005;7:107-118.

51 Vartanian LR, Shaprow JG: Effects of weight stigma on exercise motivation and behavior: a preliminary investigation among college-aged females. J Health Psychol 2008;13:131-138.

52 Leeuw M, Goossens ME, Linton SJ, Crombez G, Boersma K, Vlaeyen JW: The fear-avoidance model of musculoskeletal pain: current state of scientific evidence. J Behav Med 2007;30:77-94.

53 Vlaeyen JW, Linton SJ: Fear-avoidance and its consequences in chronic musculoskeletal pain: a state of the art. Pain 2000;85:317-332.

54 George SZ, Fritz JM, Bialosky JE, Donald DA: The effect of a fear-avoidance-based physical therapy intervention for patients with acute low back pain: results of a randomized clinical trial. Spine 2003; 28:2551-2560.

55 Elfving B, Andersson T, Grooten WJ: Low levels of physical activity in back pain patients are associated with high levels of fear-avoidance beliefs and pain catastrophizing. Physiother Res Int 2007; 12:14-24.

56 Schrop SL, Pendleton BF, McCord G, Gil KM, Stockton L, McNatt J, Gilchrist VJ: The medically underserved: who is likely to exercise and why? J Health Care Poor Underserved 2006;17:276-289.

57 Annunziato RA, Lowe MR: Taking action to lose weight: toward an understanding of individual differences. Eat Behav 2007;8:185-194.

58 McAdams MA, Van Dam RM, Hu FB: Comparison of self-reported and measured bmi as correlates of disease markers in us adults. Obesity (Silver Spring) 2007;15:188-196. 